\title{
NETWORKED RFID IN INDUSTRIAL CONTROL: CURRENT AND FUTURE
}

\author{
Duncan McFarlane \\ Centre for Distributed Automation and Control \\ Institute for Manufacturing \\ University of Cambridge, UK \\ dcm@eng.cam.ac.uk
}

\begin{abstract}
This paper introduces the notion of networked Radio Frequency Technology (RFID) and reviews the work of the Auto ID Center in providing a low cost, global networked RFID solution. The paper then examines the role of networked RFID in changing the nature of industrial control systems operations. In particular the notions of connectedness, coordination and coherence are introduced as a means of describing different stages of adoption of RFID.
\end{abstract}

\section{INTRODUCTION}

\subsection{Aims of the Paper}

Radio Frequency Identification or RFID has sprung into prominence in the last five years with the promise of providing a relatively low cost means for connecting non electronic objects to an information network (refer to Finkenzeller (1999) for technical details). In particular, the manufacturing supply chain has been established as a key sector for a major deployment of this technology. This paper introduces the concept of networked RFID and discusses its role in the development of product driven industrial control. Firstly, however, we review some of the developments in RFID.

\subsection{Developments in RFID}

The concepts behind RFID were first discussed in the mid to late 1940 's, following on from technical developments in radio communications in the 1930's and the development of radar during World War II (Landt et al., 2001). An early published work exploring RFID is the landmark paper by Harry Stockman, "Communication by Means of Reflected Power" (Stockman, 1948). Stockman stated then that "Evidently, considerable research and development work has to be done before the remaining basic problems in reflected-power communication are solved, and before the field of useful applications is explored."

The 1950s were an era of exploration of RFID techniques - several technologies related to RFID were developed such as the long-range transponder systems of "identification, friend or foe" (IFF) for aircraft. A decade of further development of 
RFID theory and applications followed, including the use of RFID by the U.S. Department of Agriculture for tracking the movement of cows. In the 1970's the very first commercial applications of the technology were deployed, and in the 1980 's commercial exploitation of RFID technology started to increase, led initially by small companies.

In the 1990's, RFID became much more widely deployed. However, these deployments were in vertical application areas, which resulted in a number of different proprietary systems being developed by the different RFID solutions providers. Each of these systems had slightly different characteristics (primarily relating to price and performance) that made them suitable for different types of application. However, the different systems were incompatible with each other - e.g. tags from one vendor would not work with readers from another. This significantly limited a doption beyond the niche vertical a pplication a reas - the interoperability needed for more widespread adoption could not be achieved without a single standard interoperable specification for the operation of RFID systems. Such standardisation was also needed to drive down costs.

The drive towards standardisation started in the late 1990's. There were a number of standardisation efforts, but the two successful projects were:

(a) the ISO 18000 series of standards that essentially specify how an RFID system should communicate information between readers and tags

(b) the Auto-ID Centre specifications on all aspects of operation of an RFID assettracking system, which has subsequently been passed onto EAN.UCC (the custodians of the common barcode) for international standardisation

The next section focuses on the Auto ID Center and its developments.

\subsection{Auto ID Center: 1999-2003}

The Auto-ID Centre (Auto-ID Center, 2003) was a university-based organisation that was formed in 1999, initially by the MIT, the Uniform Code Council, Gillette and Procter and Gamble. The motivation of the Centre was to develop a system suitable for tracking consumer packaged goods as they pass through the supply chain in order to overcome problems of shrinkage and poor on-shelf-availability of some products. The requirements for RFID in the supply chain context are in stark contrast to those applications that preceded the centre as is illustrated in Table 1 from Hodges et al. (2003) where issues of volume, complexity and life differ markedly.

The Centre expanded, involving Cambridge University in 2000 and other universities in following years, and by October 2003 had over 100 member companies, all with a common interest in either supplying or deploying such a technology in their companies. Early on in the life of the Centre, it became clear that RFID w ould form a cornerstone of the technological solution, and along with the help of some end-user and technology companies, the Centre w as instrumental in driving down the cost of RFID to a point where adoption started to become costeffective in some application areas. Part of the solution to keeping costs down is a single-minded drive to reduce RFID tag complexity, and one approach to this advocated by the Auto-ID Centre is to store as little data about products as possible actually on the tag. Instead, this information is stored on an organisation's computer network, which is much more cost-effective. 
Table 1 - RFID Application Characteristics (Hodges et al., 2003)

\begin{tabular}{|c|c|c|c|c|c|c|}
\hline & Tolling & Library & Asset & Baggage & Security & $\begin{array}{c}\text { Supply } \\
\text { Chain }\end{array}$ \\
\hline $\begin{array}{c}\text { Complexity of } \\
\text { Information on Tag }\end{array}$ & M & L & H & L & L & L \\
\hline $\begin{array}{c}\text { Single or Multiple } \\
\text { Applications for Each } \\
\text { Tag }\end{array}$ & S & S & S & S & S & M \\
\hline $\begin{array}{c}\text { Volume of Tags } \\
\text { Expected Life of Tag }\end{array}$ & H & H & H & M & M & L \\
\hline
\end{tabular}

The specific aims of the centre were thus:

1. Low Cost RFID solutions: were developed by reducing the chip price on a tag, which was achieved by reducing amount of silicon required, which required the reduction of the information stored on chip to a serial number or ID only, with all other product information held on a networked data base.

2. A Universal System: in order to achieve business justification through multiple applications/companies standard specifications were proposed for tag/reader systems, and data management and communication systems.

The Auto ID Center's development work, now carried on by the Auto ID Labs in six locations, is described next.

\section{THE ANATOMY OF NETWORKED RFID}

As discussed earlier, the key to the recent RFID deployments has been the network connection of RFID tagged objects. We now discuss requirements for such a Networked RFID approach.

\subsection{Networked RFID Requirements}

A networked RFID system generally comprises the following elements:

1. A unique identification number which is assigned to a particular item.

2. An identity tag that is attached to the item with a chip capable of storing at a minimum - the unique identification number. The tag is capable of communicating this number electronically.

3. Networked RFID readers and data processing systems that are capable of collecting signals from multiple tags at high speed (100s per second) and of preprocessing this data in order to eliminate duplications, redundancies and misreads.

4. One or more networked databases that store the product information.

With this approach, the cost of installing and maintaining such systems can be spread across several organizations while each is able to extract its own specific 
benefits from having uniquely identified items moving in, through and out of the organization's operations.

\subsection{The EPC Network}

The EPC Network is the Auto ID Center's specification for a Networked RFID system. The EPC Network consists of six fundamental technology components, which work together to bring about the vision of being able to identify any object anywhere automatically and uniquely. These are:

1) The Electronic Product Code (EPC)

2) Low-cost Tags and Readers

3) Filtering, Collection and Reporting

4) The Object Name Service (ONS)

5) The EPC Information Service (EPCIS)

6) Standardised vocabularies for communication

These six elements together form the core infrastructure of the EPC Network and provide the potential for automatic identification of any tagged product. Figure 1 illustrates a schematic of how the elements interface with each other for a toaster.

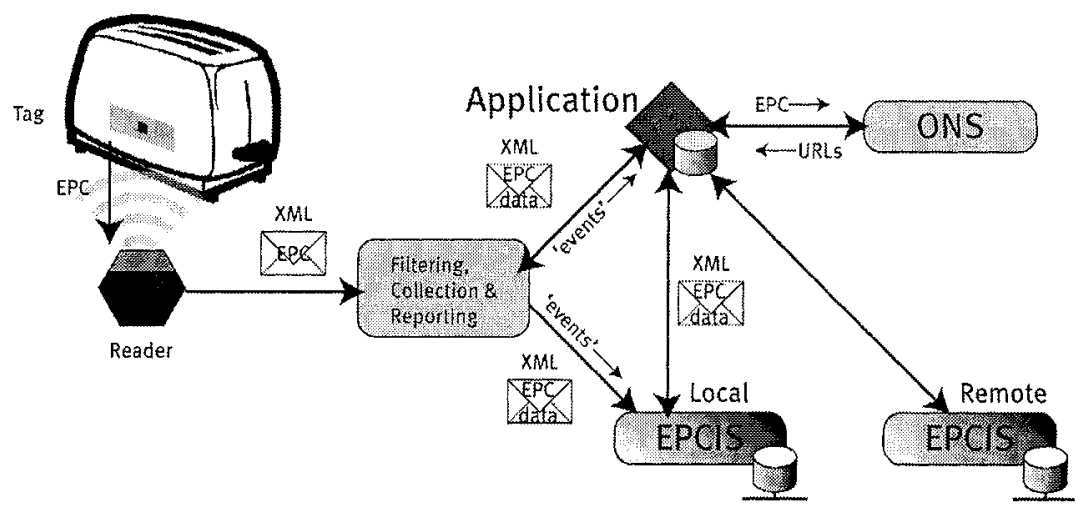

Figure 1 - Architecture of the EPC Network

We outline each component briefly below, and the reader is referred to Harrison (2004) for example for further details.

\subsubsection{The Electronic Product Code (EPC)}

The aim of the EPC is to provide a unique identifier for each object (Brock, 2001a). Designed from the outset for scalability and use with networked information systems, the EPC typically consists of three ranges of binary digits (bits) representing:

a) an EPC Manager (often the manufacturer company ID)

b) an object class (usually the product type or "SKU") and

c) a unique serial number for each instance of a product.

As well a s being the lookup 'key' to a ccess the information a bout the tagged object on the network, the EPC concept has also been an important factor in driving down the production costs of tags and readers (Sarma, 2001); by stipulating that the 
tag need only store the unique EPC identity number, it is possible to design tags with much lower on-board memory requirements, since the additional information about the tagged object can be stored in distributed networked databases, tied to the object via its EPC number.

\subsubsection{Low-cost Tags and Readers}

Radio Frequency Identification (RFID) is a key technology enabling automatic reading of multiple items simultaneously, without requiring manual scanning of each individual item. The reader emits radio waves of a particular frequency. When passive tags (called passive because they lack their own power supply) enter the range of a reader, their a ntenna a bsorb e nergy from the $r$ adio field, powering the microchip which stores the unique EPC identity code - and returning this information back to the reader via a modulation of the radio waves.

\subsubsection{Filtering, Collection and Reporting ('Savant')}

A widescale deployment of RFID tags and readers could potentially result in overloading of the information network (bandwidth and database storage capacity) with raw data from RFID readers. It is important to ensure that just significant data and 'events' a re transmitted. These software 'events' c ontain information a nd a re able to trigger processes in higher-level applications and information systems.

\subsubsection{The Object Name Service (ONS)}

The Object Name Service (ONS) is used to convert an EPC into a number of internet addresses where further information about a given object may be found. Currently, the ONS specification deals with a static i mplementation based on the Domain Name Service (DNS) which provides IP address lookup for the internet. Recognising that potentially several parties in the supply chain may also hold relevant data about an object, it is likely that static ONS will be augmented with a dynamic ONS counterpart, which is able to provide a lookup for many instances of a given product, pointing to the various other parties across the supply chain, which also hold information.

\subsubsection{The EPC Information Service (EPCIS)}

While the ONS points to various sources of information, it must be recognised that different companies will use different database vendors and different implementations and that there is currently great reluctance to share information between trading $p$ artners. However, in order to o btain maximum b enefit from the EPC Network infrastructure, companies need to share some information in order to be able to respond in a more timely manner to the new data available, e.g. allowing manufacturers to adjust production rates to synchronise with actual real-time consumer demand detected by smart shelves with embedded readers.

\subsubsection{Standardised vocabularies for communication}

Having obtained the data via ONS and EPCIS, it is important that its interpretation is unambiguous and ideally self-describing. This is the role of standardised vocabularies. Approaches based on the Extensible Markup Language (XML) provide a way of marking up structured data for communication and exchange between diverse applications and different parties (refer to (Brock, 2001b) and (Floerkmeier et al., 2003) for more details). 


\section{IMPACT OF NETWORKED RFID ON INDUSTRIAL CONTROL}

Having established the structure and functionality of a networked RFID system, we now focus on its role in an industrial control environment. The first point to make is that although the networked RFID system is essentially and information providing Service, in an industrial control context it needs to be considered as part of a closed loop process (see Figure 2). In understanding the way in which RFID is introduced into the closed loop we find it helpful to consider three stages of integration:

1. Connection: the stage at which the physical integration of RFID data with the existing sensors used in the operation is achieved. The data at this stage is merely used for monitoring purposes and does not influence the resulting decisions or actions.

2. Coordination: the stage in which networked RFID data is exploited to provide an increased quality of product information in the closed loop which can enhance the decision making and execution processes.

3. Coherence: the availability of the increased quality of product information leads to a reeingeering of the decision making process and/or the physical operation being controlled.

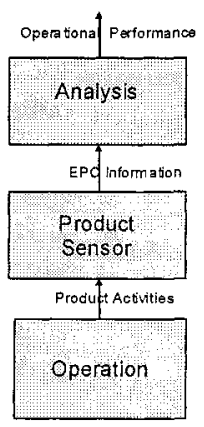

a) Open-Loop RFID

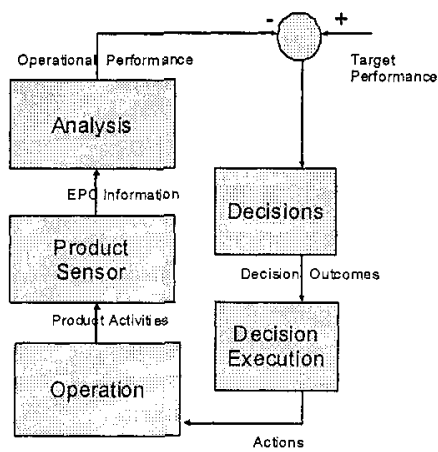

b) Closed-Loop RFID

Figure 2 - Open Loops vs Closed Loops RFID

We will briefly discuss each of these stages, and comment on their relevance to ongoing developments in RFID-based industrial control.

\subsection{Connection: RFID As An Additional Sensor in the Closed Loop}

The most fundamental impact of the introduction of tagged products is that an additional sensor stream is introduced into the industrial control environment. Note that bar coding and other direct product inspection systems rarely play a role in industrial control environments owing to their difficulty in achieving reliable automation. Hence, typically, information as to the identity and movement of 
products is currently determined indirectly through the combination of proximity sensors and manual records.

The introduction of RFID enables a more accurate and automatable form of product monitoring, and can enable regular updating of production and order status, inventory levels etc.

In mid 2004, this stage of deployment represents the status quo in the commercial use of networked RFID. It is observed that many potential implementers are seeking simply to understand the issues and challenges in connecting RFID while work in establishing a business basis proceeds in parallel. Some comments on achieving RFID connections are provided in (Chang et al., 2004).

\subsection{Coordination: Quantifying Product Information Quality}

The main value of the introduction of a networked RFID solution such as the EPC Network is in enhancing the quality of product information available to make decisions. By product information quality, we refer to properties or dimensions such as:

- accuracy: the precision and reliability associated with the collection of product information

- completeness: the amount of product information relevant for a given decision, that is available

- timeliness: the timeliness of the availability of product information

A qualitative assessment of different product information sources against these dimensions is given in Figure 3. In this diagram we distinguish between the stand alone and networked RFID solutions - the latter with direct data base access has the ability to provide a more complete level of information about a given item.

The coordination of networked RFID data raises a number of questions about the implementation of the system which are being addressed both academically and industrially at present:

- How should the RFID hardware be arranged to maximise the impact on the industrial control system?

- What are the other sensing issues, and how should the RFID data be best coordinated with these sensors to maximise the effectiveness of decisions made?

- How sh ould the R FID data be filtered and prepared to b e most e ffectively integrated?

- How can the impact of better product information on resulting decisions be qualified?

Any of the industrial developments being reported in the commercial press at present (RFID Journal, 2004) refer to the management of such issues, and academically, work has been performed to provide a theoretical framework for examining the role of information quality (McFarlane, 2003; McFarlane et al. 2003b) and its benefits, e.g. (Parlikad et al., 2004). 


\section{ACCURACY}

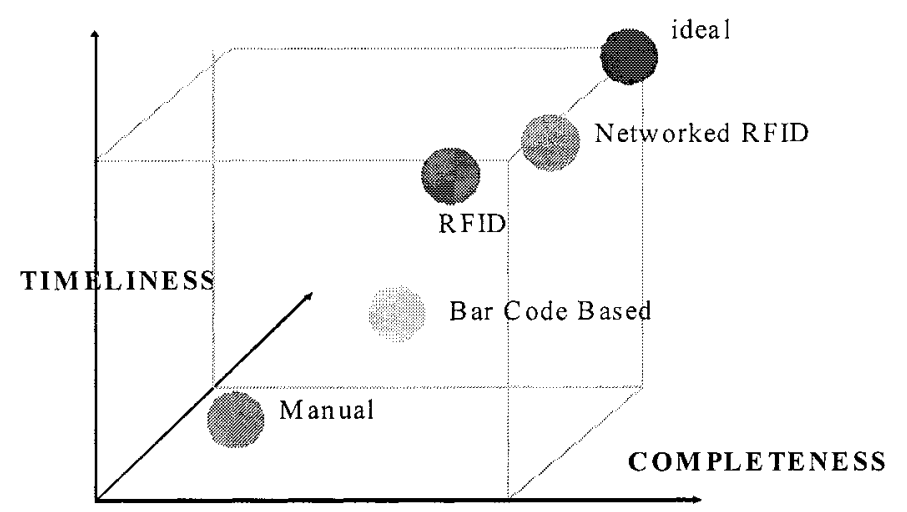

Figure 3 - Product Information Quality from Different Sources

\subsection{Coherence: Networked RFID Supporting Product Intelligence}

Many pundits have indicated that RFID may become a disruptive technology for the industrial supply chain, e.g. (Sheffi, 2004). The ready availability of high quality product data can not only enhance existing decision making processes in the supply chain (e.g. inventory management, quality control, shelf replenishment) but can lead to a radical rethinking of the nature of the decisions themselves and the resulting actions. For example, in (Wong et al., 2002) the nature of retail shelf replenishment is examined in detail and in (Fletcher et al., 2003) the role of RFID in developing a radical mass customised packaging environment is discussed. Essentially, a networked, RFID tagged object can play a rather different role in the operations it is subject to, compared to the way it is managed today.

In particular, the introduction of a networked RFID system can alter the role of a product from a purely passive one, to one in which a product - representing a section of a customer order - can actively influence its own production, distribution, storage, retail etc. We refer to this as an "intelligent product" - the notion and uses of intelligent products have also been reported in (Bajic et $a l ., 2002$ ) and (Karkannian et al., 2003). We formalise the concept of an intelligent product with the following working definition (McFarlane et al., 2003a):

An intelligent product is a physical and information based representation of an item for retail which:

1. possesses a unique identification

2. is capable of communicating effectively with its environment

3. can retain or store data about itself

4. deploys a language which can articulate its features and requirements for its production, usage, disposal etc...

5. is capable of participating in or making decisions relevant to its own destiny on a continuous basis

The corresponding intelligent product for a soft drink can is illustrated in Figure 4 in which the physical can is connected to a network and thus to both information stored about it and also to a decision making (software) agent acting on its behalf. The 
concept of a software agent is important to the following discussion and is defined as:

A software agent is a distinct software process, which can reason independently, and can react to change induced upon it by other agents and its environment, and is able to cooperate with other agents.

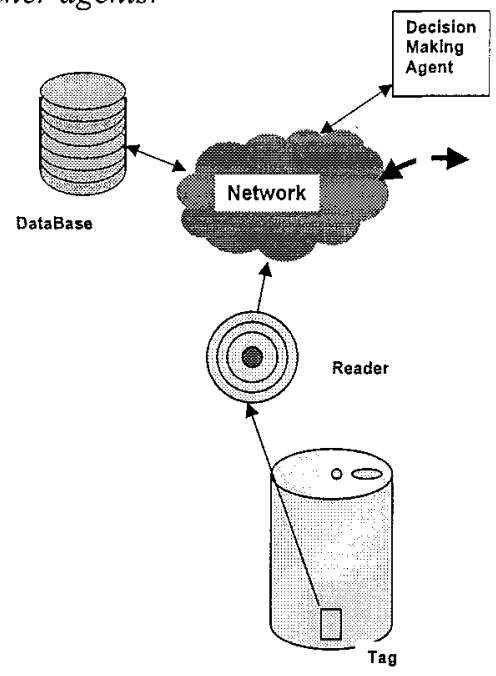

Figure 4 - "Intelligent drink can"

The intelligent product, defined here, is hence an extension of the product identification system provided by a networked RFID system - incorporating a software agent that is capable of supporting decisions made on behalf of the product.

The notion of software agents in the development of industrial control systems has been discussed for some time (see for example (Marik et al., 2002; Deen, 2003) and the references therein). Software agents have been used to develop a radical set of future industrial control architectures in which disruption management, rapid reconfiguration and low cost customisation are the key drivers. The introduction of networked RFID, coupled to a software agent based industrial control environment can be seen to enable key elements of a radically new control system in which products as part of customer orders drive their own operations. The reader is referred to (McFarlane et al., 2003a; Harrison et al., 2004) for more details on this concept in the manufacturing domain.

\section{SUMMARY}

This paper introduced the networked RFID concept and summarised the key ways in which it can impact on industrial control systems. The interested reader is referred to the Cambridge Auto ID Labs activities for more details (Auto ID Labs, 2004).

\section{ACKNOWLEDGEMENTS}

The author would like to thank his colleagues at the Auto ID Labs at Cambridge and before that at the Cambridge Auto ID Center for their significant contributions to the 
developments that are summarised in this paper. The financial contributions of the large number of industrial sponsors of this work are also gratefully acknowledged.

\section{REFERENCES}

1. Auto-ID Centre, Auto ID Center website archive: http://archive.epcglobalinc. org/index.asp, 2003

2. Auto ID Labs@ Cambridge, website: www.autoidlabs.org/cambridge, 2004

3. Bajic E, Chaxel F. Holonic Manufacturing with Intelligent Objects. In Proceedings of 5th IFIP International Conference on Information Technology for Balanced automation systems In Manufacturing and Services, Cancun, Mexico, 2002.

4. Brock DL. Electronic Product Code ${ }^{\mathrm{TM}}\left(\mathrm{EPC}^{\mathrm{TM}}\right)$ - A Naming Scheme for Physical Objects. Auto-ID Center White Paper, 2001.

5. Brock DL, The Physical Markup Language (PML) - A Universal Language for Physical Objects. Auto-ID Center White Paper, 2001.

6. Chang Y, McFarlane D. Supply Chain Management Using AUTO-ID Technology - Preparing For Real Time, Item Level Supply Chain Management. In Evolution of Supply Chain Management: Symbiosis of Adaptive Value Networks and ICT, Kluwer Academic Publisher, USA, 2004.

7. Deen SM. (Ed). Agent Based Manufacturing: Advances In The Holonic Approach, Springer-Verlag Berlin Heidelberg, 2003.

8. Finkenzeller K. RFID Handbook. 1st edition, Wiley \& Sons LTD, 1999.

9. Fletcher M, McFarlane D, Lucas A, Brusey J, Jarvis D. The Cambridge Packing Cell - A Holonic Enterprise Demonstrator. In Multi-Agent Systems and Applications III, LNAI 2691, Springer Verlag, Heidelberg, 2003, pp. 533-543.

10. Floerkemeier C, Anarkat D, O sinski T, H arrison M. P ML C ore S pecification 1.0. A uto-ID C enter White Paper, 2003.

11. Harrison M, McFarlane D, Parlikad A, Wong C Y. Information management in the product lifecycle The role of networked RFID. Accepted for $2^{\text {nd }}$ International Conference on Industrial Informatics, Berlin, 2004.

12. Harrison M. EPC Information Service - Data Model and Queries. Auto-ID Center White Paper, 2004.

13. Hodges S, McFarlane D. Radio frequency identification: technology, applications and impact. In Proceedings of the OECD Conference, Brussels, 2003.

14. Karkkainen M, et al. Intelligent products - a step towards a more effective project delivery chain. In Computers In Industry 50, Elsevier Science, 2003, pp. 141-151.

15. Landt J, Catlin B. Shrouds of Time: The history of RFID. Published by AIM, The Association for Automatic Identification and Data Capture Technologies, http://www.aimglobal.org/ technologies/rfid/resources/shrouds_of_time.pdf, 2001.

16. Marik V, Stepankova O, Krautwurmova H, Luck M. (Eds.). Multi-Agent Systems and Applications II, LNAI 2322, Springer-Verlag, Berlin Heidelberg, 2002.

17. McFarlane D. Product Identity and Its Impact on Discrete Event Observability. In Proceedings of ECC, Cambridge, UK, 2003.

18. McFarlane D, Sarma S, Chirn J-L, Wong C Y, Ashton K. The Intelligent Product In Manufacturing Control And Management. Engineering Applications of Artificial Intelligence: special issue on Intelligent Manufacturing, Vol. 16, No. 4, 2003, pp. 365-376.

19. McFarlane D, Sheffi Y. The Impact of Automatic Identification on Supply Chain Operations. International Journal of Logistics Management, Vol. 14, No. 1, 2003, pp. 1-17

20. Parlikad A, McFarlane D. Investigating The Role Of Product Information In End-Of-Life Decision Making. Proceedings of $11^{\text {th }}$ IFAC Symposium on Information Control Problems in Manufacturing, San Salvador, Brazil, 2004.

21. RFID Journal, website: www.rfidjournal.com, 2004.

22. Sarma S. Towards the $5 \phi$ Tag. Auto ID Center White Paper MIT-AUTOID-WH-001, http://www.autoidcenter.org/research, 2001.

23. Sheffi Y. RFID and Innovation, In Proceedings of the MIT Summer School in Logistics and Operations Management, 2004.

24. Stockman H. Communication by Means of Reflected Power. In Proceedings of the IRE, 1948, pp. 1196-1204.

25. Wong CY, McFarlane D, Zahrudin A, et al. The Intelligent Product Driven Supply Chain. In Proceedings of IEEE International Conference on Systems, Man and Cybernetics, Hammamet, Tunisia, 2002. 